\title{
CENTRALIZAÇÃO E DESCENTRALIZAÇÃO NAS POLÍTICAS EDUCACIONAIS DO BRASIL NO PÓS-30*
}

\section{Angela Maria Hidalgo}

\section{Professora do Depto. de Educação da Universidade Estadual de Londrina; Doutoranda em Educação pela} Universidade Estadual Paulista - Campus de Marília.

Considerando a política educacional como uma das políticas públicas, pretendemos identificar as influências dos discursos de dois educadores nacionais, Fernando de Azevedo e Anísio Teixeira, no âmbito da política educacional. Estes autores, em diferentes momentos, defenderam, respectivamente, a centralização e a descentralização da ação governamental no âmbito educacional, e tiveram suas propostas em evidência, relacionadas com a concepção de nacionalismo/internacionalismo da política econômica implementada.

Palavras-chave: política educacional; centralização; descentralização; história da educação.

\section{INTRODUÇÃO}

\section{A}

bordaremos as propostas de centralização $\mathrm{e}$ descentralização do Estado na definição das políticas educacionais num contexto mais amplo, qual seja, o da definição da política econômica implementada no Brasil em relação aos centros capitalistas hegemônicos.

Partimos da premissa de que o liberalismo, enquanto expressão filosófica do capital, através da mediação de alguns intelectuais reformula elementos vindos de diversos setores da sociedade, incorporando-os ao seu arcabouço teórico, como parte de um mecanismo de recomposição interna.

Consideramos o discurso de Fernando de Azevedo para demonstrar como determinados temas e problemáticas tratados pelos educadores em determinados momentos serviram como anteparo para um processo de ocultamento de propostas alternativas para a educação.

Analisamos, portanto, como nas décadas de 1930, 1950 e 1970 as propostas de descentralização/centralização dos sistemas de ensino se relacionam com as opções de adoção de um modelo econômico associado e interdependente, ou de uma política econômica nacionalista que tenta manter no âmbito nacional o centro das decisões sobre as políticas econômicas implementadas.
Quando da análise das diretrizes do Banco Mundial para a educação dos países sob sua influência, como parte do processo de globalização da economia, indicamos que as propostas de descentralização e privatização para a área estão relacionadas com as tendências de governo descentralizado, portanto de fortalecimento dos segmentos locais da sociedade civil, para que a comunidade assuma as decisões e encargos na resolução dos problemas públicos, como parte das necessidades de enxugamento do Estado.

\section{POLARIZAÇÃO VELHO X NOVO: HOMOGENEIZAÇÃO QUE OBSCURECE EMBATES}

O conflito entre católicos e reformadores, amplamente discutido pela historiografia educacional no contex to em que a Revolução de 30 abria perspectivas de participação na condução das reformas educacionais, refletia, na verdade, mais uma disputa por parte de grupos que buscavam exercer maior influência no direcionamento do aparelho estatal do que a defesa de princípios filosóficos. No nível ideológico, as reivindicações e manifestações dos reformadores trouxeram como conseqüência uma desarticulação de propostas historicamente elaboradas pela classe popular. Demandas de

\footnotetext{
* O texto é uma adaptação da monografia intitulada Centralização e descentralização nas políticas educacionais do Brasil pós 30: a busca de sua natureza e sentido, apresentada como trabalho de conclusão do curso de Especialização em Sociologia e Sociologia da Educação, da UEL, em dezembro de 1996, sob orientação da professora Maria Regina Clivati Capelo.
} 
uma escola pública, gratuita e universal adquiriram, através desses educadores, um caráter de público subordinado ao Estado. Manifestaram uma concepção de público que necessariamente tivesse o Estado como mediador e, consequientemente, uma subordinação das ações da sociedade civil no âmbito educacional em face da burocracia estatal.

Através de uma análise do pensamento de Fernando de Azevedo exposto em A cultura brasileira, CARVALHO (1988) demonstra que esse autor reduz os conflitos políticos ao debate entre o "novo" e o "velho" na sociedade brasileira, atribuindo à chamada por ele de "zona de pensamento perigoso" as propostas elaboradas a partir de alternativas políticas que vinham sendo construídas.

Este discurso obscurece um debate real ocorrido no interior do movimento educacional da década de 20, homogeneizando as propostas elaboradas no período, as quais têm que ser revistas pela historiografia educacional.

DE DECCA (1984) demonstra como no período de 1928-1929, mediante a organização da classe proletária em um partido político, ocorre uma reação das elites econômicas que, através do tema da industrialização e da difusão de uma visão das organizações trabalhistas enquanto anárquicas, provoca uma sistemática desarticulação deste movimento.

A obra de Fernando de Azevedo sobre os embates políticos do período não fazem qualquer menção a estes embates travados entre capital e trabalho, restringindo-se a polarizar a disputa política entre os interesses da "velha" oligarquia cafeeira e os das "novas" classes emergentes do processo de industrialização.

No campo educacional, o embate que ficou em evidência naquele período restringiu-se também aos interesses privatistas e corporativistas do grupo católico com os educadores renovadores.

Com referência ao movimento educacional nos anos 30, CARVALHO (1988) esclarece que católicos e liberais, que nos anos 20 atuaram juntos na Associação Brasileira de Educação ( $\mathrm{ABE}$ ) visando desenvolver um projeto para a formação de uma cultura nacional através da formação das “elites diretoras", com ênfase na formação do magistério, após a revolução passam a disputar espaços junto à esfera de poder com o intento de influir nas decisões governamentais.

Porém, de forma ainda sutil, esclarece que a preocupação dos reformadores era, na verdade, que o avanço do comunismo como proposta política estivesse interferindo no cotidiano escolar. Conforme CARVALHO (1989, p.34):

\footnotetext{
"Sedimentados sobre o solo comum de convicções e interesses amplamente partilhados, tais propostas tinham na questão do ensino religioso apenas um de seus pontos programáticos. 'Deixemos por favor de Deus', adverte Leonardo Van Acker, 'as questiúnculas sobre o b-a-ba. Nem nos salvará uma horinha de ensino religioso, se o resto do sistema educacional for socialista ou comunista bem intencionado!! Seria um balde de água doce no mar'”.
}

Quanto ao posicionamento da Igreja católica, fica mais que explícita, através das encíclicas papais, a preocu- pação de combater o socialismo como ideologia através da educação administrada por suas instituições.

DE DECCA (1984) esclarece que em 1928 e 1929 a classe dos industriais utilizou-se do tema da industrialização e, em 1931, do tema nacionalismo como mecanismo ideológico para combater a mobilização da classe operária que se articulava em torno do Bloco Operário Camponês e que obtinha avanços políticos significativos no período.

Podemos considerar, portanto, que uma significativa organização partidária dos operários não foi suficientemente considerada e analisada pela historiografia na área da educação, quanto ao seu significado e repercussões no movimento dos educadores no período.

\section{FERNANDO DE AZEVEDO: ESTADO FORTE - CENTRALIZAÇÃO E DUALI- DADE}

Neste momento pretendemos fazer uma crítica necessária a alguns pontos da análise realizada por Fernando de Azevedo em $A$ cultura brasileira (AZEVEDO, 1976) a respeito da educação no final do Império e início da República brasileiros, mais especificamente a respeito da análise que o autor faz da dualidade do sistema de ensino e de sua defesa da centralização do Estado na questão da educação. Esta necessidade se coloca sobretudo porque este autor ocupou e ocupa destaque na historiografia brasileira na área da educação, principalmente por ser considerado objetivo e imparcial em suas análises.

A crítica que Azevedo dirigiu à dualidade do sistema de ensino refere-se à dualidade entre sistema estadual e sistema federal de ensino e à falta de uma unidade nacional dada pelo Estado. Aproximando-se dos princípios do positivismo de Durkheim, ele mostra clara preocupação com a formação das elites dirigentes através das universidades e com a formação de técnicos requeridos para a indústria através do ensino técnico secundário, arregimentados nas classes trabalhadoras. Estes princípios demonstram, na verdade, a defesa de uma unidade dirigida por um "Estado forte", comandado pela elite nacional, que perpetue uma dualidade de classes através da educação.

DURKHEIM (1984), por considerar a divisão social do trabalho como um processo natural e harmônico do desenvolvimento da sociedade industrial, onde cada atividade tem um caráter de complementaridade em relação à outra, e também para justificar a necessidade de formação dos Estados nacionais modernos, explicita e defende a existência de um sistema educacional uno e múltiplo, simultaneamente.

“Cada profissão (...) requer aptidões particulares e conhecimento específicos (...) e uma vez que a criança deve ser preparada com vista à função que será chamada a preencher, a educação, a partir de uma certa idade, não pode continuar a ser a mesma para todos os sujeitos a que é aplicada." (DURKHEIM, 1984, p.14) 
Mais adiante defende:

"Não existe povo onde não existir um certo número de idéias, de sentimento e práticas que a educação inculcar em todas as crianças, indistintamente, qualquer que seja a categoria social a que pertençam". (idem, p.15).

WARDE (1984), ao defender a tese de que o liberalismo não apenas representa a ideologia do capitalismo, como também o justifica, dando-lhe suporte teórico, apresenta os mecanismos de recomposição deste pensamento em face do desenvolvimento das forças proletárias emergentes e considera o positivismo como uma das doutrinas de pretensa reação anti-liberal, mas que, na verdade, acabou "fertilizandoo".

Portanto, essa autora apresenta-nos Durkheim como típico pensador do liberalismo. As elaborações teóricas deste contribuem para o processo de "publicização da ordem privada", no qual a sociedade civil passou de espaço do indivíduo para espaço do grupo social, no período de transição do capitalismo da fase concorrencial para a monopolística. Esse raciocínio embasa

"a idéia de um Estado forte que vai retraindo cada vez mais a crença de que a participação das classes operárias nos mecanismos formais da 'democracia' poderia ser controlada seja pelas regras jurídicas partidárias e pelas regras de participação partidária no parlamento, seja pelos processos educativos que preparariam adequadamente as classes trabalhadoras para a vida pública (política)." (WARDE, 1984, p.112)

Fernando de Azevedo passou a ser para a educação um dos intelectuais cujas idéias acabaram por defender e justificar o Estado Novo e toda a sua política nacionalista e centralizadora, encaminhada de forma autoritária, que, no contexto internacional, encontrava respaldo no fascismo europeu, cujo objetivo central era combater as organizações proletárias que então se articulavam, inspiradas na adoção do socialismo enquanto modelo econômico em alguns países.

\section{NACIONALISMO/INTERNACIO- NALISMO DO ESTADO: CORRE- LAÇÃO DE FORÇAS QUE ASSU- MEM A CENTRALIZAÇÃO/DES- CENTRALIZAÇÃO}

A partir das considerações de IANNI (1971) sobre a correlação de forças políticas e a consequiente política econômica adotada pelo país nos períodos 1946-1950 e 1951-1954, tentaremos situar o discurso de Anísio Teixeira neste embate, apresentando sua mediação no nível da sociedade civil, entre a infra-estrutura e a superestrutura jurídico-política; as teses por ele defendidas; e suas influências no processo de elaboração da Lei de Diretrizes e Bases (LDB) de 1961.

Segundo Ianni, o golpe de estado em 29 de outubro de 1945, que depõe Vargas, coloca fim ao Estado Novo e inicia um processo de "redemocratização" no país, o que, na verdade, foi resultado tanto de "interesses de grupos conservadores brasileiros como interesses econômicos e políticos estrangeiros, principalmente norte-americanos" (IANNI, 1971, p.79) contrários à política estatizante de Vargas, que tentava avançar no desenvolvimento econômico, de forma autônoma em relação aos centros internacionais hegemônicos, desenvolvendo, para isso, uma política de alianças com as massas populares e tendo ainda, como base de apoio, a burocracia estatal e uma fração da burguesia industrial.

Adotou-se, a partir de 1946, com o governo Dutra e a nova Constituição, os princípios liberais de livre iniciativa e "igualdade de oportunidades para nacionais e estrangeiros", que criavam novas condições para a entrada e a saída do capital estrangeiro do país, assim como "o poder público voltava à condição de guardião das 'regras do jogo' econômico, segundo a doutrina liberal e as conveniências das empresas privadas mais poderosas". (idem, p.84)

Desenvolve-se, também, nesse período, uma política de confisco salarial, não havendo elevação do salário mínimo, apesar da inflação crescente.

Assumindo o Partido Comunista Brasileiro (PCB) significação nacional e conseguindo expressiva mobilização da opinião pública, o governo adota, a partir de 1946, uma ação repressiva que em 1947 culmina no cancelamento do registro do partido. Como conseqüência, tem-se a aglutinação da oposição no Partido Trabalhista Brasileiro (PTB) e o ressurgimento da liderança popular de Vargas.

Lembra o autor a importância de se considerar, neste período, para um melhor entendimento das questões políticas internas, o contexto internacional de desenvolvimento da guerra fria e sua extensão após a Segunda Guerra Mundial para os países da América Latina, assim como o lançamento da Doutrina Truman em 1947 como forma de justificar, a partir das consequiências do conflito internacional nos países europeus, a interferência norte-americana na política dos países dependentes em face dos interesses da expansão capitalista.

No novo período do governo Vargas (1951-1954), o poder público retoma uma política de intervenção na economia visando a resolução dos problemas econômicos emergentes e a criação de infra-estrutura necessária ao desenvolvimento industrial em fase de ampla expansão. Porém, esta política intervencionista encontra uma conjuntura política diferente da do período anterior. Com o processo de urbanização, decorrente do desenvolvimento dos setores terciário e industrial, desenvolve-se uma melhor configuração na composição de classes da sociedade, tornando-se mais nítido o antagonismo entre o proletariado e a burguesia industrial, diferenciada internamente em três grupos: pequena burguesia nacional, grande burguesia nacional e grande burguesia industrial internacional. Da mesma forma, a classe média encontra-se ampliada, juntamente com os setores agrário, comercial e financeiro da burguesia. Considera-se também um aprofundamento das relações entre o Brasil e os Estados 
Unidos, destacando o início das atividades da Comissão Mista Brasil-Estados Unidos, em 1948, que, no governo Vargas, terá seus projetos financiados e concretizados.

Esta nova correlação de forças sociais delineava para o país três alternativas de desenvolvimento econômico. Primeiro, a opção adotada no governo Dutra, de desenvolvimento econômico associado e interdependente, que "admitia que o subsistema econômico brasileiro somente poderia progredir se mantivesse e desenvolvesse os vínculos com os centros hegemônicos, para obtenção de capital e tecnologia". (idem, p.134) Segundo, a alternativa proposta pelo PCB, via estatização da economia para socialização da produção. E, por último, a opção que teria por objetivo o desenvolvimento de um "capitalismo nacional no Brasil", a qual buscava, via "intervencionismo estatal adotar soluções de política econômica do tipo nacionalista, (...) que acelerasse a nacionalização dos centros de decisão sobre as diretrizes da economia do país". (idem, p.135)

O autor identifica esta última alternativa como a adotada pelo governo Vargas, que contava com o apoio de grupos da classe média, da pequena burguesia, de parte da grande burguesia industrial nacional, de setores do Exército, de intelectuais e do proletariado. $\mathrm{O}$ apoio das massas, que caracterizava a estratégia política de Vargas de demonstração de poder, fez com que denominassem seu governo de "República Sindicalista". Quando da insatisfação dos setores dominantes da economia com a orientação da política econômica adotada pelo governo, estes utilizam-se desse apoio para amedrontar a classe média e obter seu apoio político para a deposição de Vargas.

O capital internacional, preocupado com a tendência estatizante e intervencionista da política interna, adota como prática a associação de capitais com investidores nacionais, contornando o nacionalismo local. Neste cenário Vargas é deposto em 1954, quando, após um período de crise política, tem início o governo de Juscelino Kubitschek.

O Programa de Metas, estabelecido então, representou um significativo aprofundamento das relações entre o Estado e a economia, tendo em vista impulsionar o desenvolvimento econômico, calcado na industrialização do setor privado nacional e estrangeiro.

Uma mudança qualitativa destas relações é destacada como a opção por um desenvolvimento econômico associado e dependente.

\begin{abstract}
"Nessas condições, desenvolveu-se ainda mais o modo capitalista de produção no Brasil, como subsistema do sistema capitalista mundial. Em consequiência, acentuou-se a divisão social do trabalho e a diferenciação social interna da sociedade brasileira". (idem, p.169)
\end{abstract}

A partir deste quadro, é oportuno refletir as seguintes questões: fica claro na análise de Fernando de Azevedo, com relação à problemática educacional brasileira, no período 1930-1940, que sua preocupação principal era a descentralização da política educacional, propondo um governo forte, que centralizasse o desenvolvimento de uma política educacional nacional. Este pensamento teve ressonância, no período destacado, em detrimento de outras posições. Já na visão de Anísio Teixeira, a centralização do sistema educacional pelo poder central é um dos pontos responsáveis pelos males da educação e, por isso, propõe a descentralização do sistema de ensino. Este pensamento adquire ressonância, sobretudo no período 1950-1960. Perguntamos: que relação existe entre estas proposições e os contextos socioeconômico e político do período em que foram colocadas em destaque? Por quê, em determinados momentos históricos, pensadores imbuídos de determinados sistemas de pensamento filosófico conseguem com suas teorias e proposições influir na política educacional fazendo com que se adote um sistema em detrimento de outros?

Não defendemos que as determinações da infra-estrutura econômica condicionem imediata e diretamente as instituições da superestrutura jurídico-política. Entretanto, sabemos que existe uma relação dialética entre essas instâncias, mediada até mesmo pelos intelectuais enquanto representantes de determinados interesses de classe.

HORTA (1989) chama atenção para a relação existente entre as posições centralizadoras/descentralizadoras no âmbito educacional com as concepções de nacionalismo/internacionalismo destas mesmas posições. Apresenta os educadores liberais defendendo propostas descentralizadoras em contraposição às iniciativas do Governo Provisório.

Este autor demonstra ainda, através dos discursos dos ministros do Governo Provisório, que, a partir de 1930, “a crença de que a solução para a educação brasileira estaria na afirmação de sua dimensão nacional, em oposição às soluções regionais, só poderia partir daqueles que se opunham ao liberalismo". (HORTA, 1989, p.11)

Destacamos também o trabalho de SCHWARTZMAN et al (1984), que, em sua análise do ministério Capanema, salientam a associação entre as secretarias estaduais de educação e as forças policiais na função repressiva enquanto ações complementares de uma vinculação entre a resolução dos problemas nacionais e uma estrutura de poder centralizado no desenvolvimento de uma política de nacionalização.

HORTA (1989, p.11) destaca que a defesa por parte dos educadores liberais da "necessidade de se incentivar, através da educação, a cooperação internacional e a fraternidade universal", assume, a partir de 1947, uma conotação diferente, explicitada nesta afirmação: "A solidariedade e a fraternidade universais passam a ser vistas à luz da ideologia da 'guerra fria' a transformarem-se em solidariedade ao bloco ocidental, ou seja, ao mundo livre, ameaçado pelo comunismo".

Anísio Teixeira, em depoimento à Câmara dos Deputados em 1952, para debate sobre a Lei de Diretrizes e Bases da Educação Nacional (LDBN), que tramitava desde 1948, defende

"uma descentralização corajosa do ensino brasileiro (...). Ficar tudo em mãos do governo federal representa, em vez de estímulo, um fator de inibição para os múltiplos responsáveis, que devem ser convocados a trazer a sua contribuição. Desejo acentuar que este é realmente o mal dos males da situação educacional brasileira. A 'oficialização' —- pelo regime de 
equiparações - de todo o ensino, particular e público, sob um modelo uniforme e rígido, fiscalizado tão somente nos seus aspectos extrínsecos, não só permite, como promove, a falta de autenticidade do ensino nacional". (TEIXEIRA, 1976, p.168-171)

Teixeira situa ainda o problema educacional como um problema econômico em face da necessidade de formação de mão-de-obra qualificada e de técnicos de nível superior, sem os quais não é possível levar adiante o desenvolvimento industrial almejado.

Sugere que o governo federal se constitua em órgão de supervisão e assistência técnica e financeira do ensino, assumindo, assim, um papel de orientador e estimulador, através da implantação de um sistema de classificação das escolas em escala nacional, estadual e municipal. "Temos que voltar ao regime do mérito". (idem, p.180) Propõe que a autonomia atingida pelo estado se transfira para o município, através da criação de conselhos de educação.

Quando avalia a lei, finalmente aprovada em 1961, considera-a como "meia vitória, mas vitória", por avaliar a possibilidade de os estados, através de atos complementares, procederem à execução da LDB, ficando assim parcialmente garantida a possibilidade da descentralização tão defendida por este.

"O País está, quanto ao ensino, a experimentar um sistema novo de descentralização e cooperação voluntária, com o estabelecimento de vinte e dois sistemas estaduais independentes de ensino, compreendendo as escolas públicas e as particulares, e o sistema federal de natureza supletiva". (idem, p.259)

Percebe-se, portanto, como a correlação de forças na sociedade legitima determinados grupos no poder, os quais direcionam o desenvolvimento econômico capitalista para os centros hegemônicos e adotam determinadas concepções de nacionalismo/internacionalismo. Portanto, na definição da política educacional, há, por parte do aparato estatal, um processo de incorporação de determinados discursos ao corpo legal, sob nova roupagem, como processo de recomposição da hegemonia do capital.

\section{4: ESTADO INTERVENTOR - CONCEPÇÃO TECNOCRÁTICA ECONÔMICA E SOCIAL}

A partir das contradições do populismo na política brasileira, desencadeando a "crise da democracia representativa" (IANNI,1971), pretendemos apontar as relações entre a adoção do modelo de desenvolvimento econômico escolhido pelo regime militar de 1964, o liberalismo enquanto ideologia do capital, os elementos do "modelo de democracia planificada de Mannheim", e as diretrizes da política educacional que apontam o desenvolvimento de uma racionalidade tecnocrática como elemento centralizador do poder decisório no período.
Ianni aponta dois aspectos essenciais da crise brasileira entre 1961 e 1964: a crise econômica e a crise política, ambas, naturalmente, inter-relacionadas.

Quanto ao aspecto econômico, ressalta a redução dos índices de investimentos na economia com a diminuição da entrada de capital externo, a redução da taxa de lucro e a conseqüente alta da inflação. Além da necessidade da elaboração de novas propostas de desenvolvimento econômico diante do esgotamento da "etapa de substituição das importações", esta necessidade gera a obrigatória adoção de uma das opções de direcionamento da política econômica: investir na expansão do capitalismo nacional ou acelerar a internacionalização - dilema este não encarado pelos governos populistas anteriores, que se caracterizaram pelo caráter ambíguo das medidas econômicas adotadas.

Quanto ao aspecto político da crise, Ianni destaca crescente radicalização das posições dos partidos políticos, polarizados entre a esquerda e a direita, em face de uma retração dos partidos liberais de centro. Aponta ainda a politização crescente das massas urbanas em razão dos debates em torno das reformas de base. A necessidade das reformas institucionais traz à tona uma dissociação de interesses entre o Poder Legislativo e o Poder Executivo. Explica que, neste período, o Congresso Nacional era composto em sua grande maioria por políticos ligados à sociedade agrária, e, portanto, com interesses voltados para atividades econômicas primário-exportadoras. Por outro lado, o Poder Executivo estava imbuído dos interesses ligados à sociedade urbano-industrial. Este divórcio, segundo o autor, alimenta e desenvolve a crise, também relacionada ao modelo de sociedade a ser adotado. É neste contexto que uma aliança política civil-militar toma o poder e desenvolve um regime calcado no autoritarismo crescente ao longo das décadas de 60 e 70, para impor o modelo de desenvolvimento econômico associado e dependente dos centros hegemônicos internacionais.

Como forma de viabilizar os princípios econômicos e políticos do grupo que assumia o poder (representando, é claro, os interesses de outros grupos econômicos), entre 1964 e 1966, através dos atos institucionais, foi instituída a hegemonia absoluta do Poder Executivo sobre o Poder Legislativo.

Abordando os aspectos da política econômica adotada após 1964, Ianni explicita a consonância desta com os interesses da reprodução ampliada do capital e da expansão da empresa privada nacional e estrangeira, para tanto assumindo um aspecto interventor mais profundo e sistemático. Desenvolve-se, portanto, uma estrutura técnico-burocrática com o papel de regular as relações de produção e as forças produtivas do país, assumindo um discurso de neutralidade e necessidade da planificação da política econômica governamental.

"Em poucos anos, tornava-se predominante uma nova ideologia sobre o significado da atividade política, os papéis dos partidos políticos, os limites da atuação do Legislativo, a importância da tecnoestrutura, a necessidade do planejamento centralizado, etc. Em conseqüência, o próprio governo tomou a iniciativa, 
no combate contra a 'liberal democracia'. Devido ao agravamento das tensões entre os grupos e classes sociais, em âmbito nacional e internacional, as forças políticas e econômicas dominantes decidiram passar à discussão e condenação aberta da democracia liberal, em favor da 'democracia social"'. (IANNI, 1971, p.246)

Neste momento destacamos a tese de que o liberalismo, enquanto ideologia do capital, sofre determinadas mutações pela mediação dos "intelectuais orgânicos", apropriando-se de elementos até mesmo contraditórios aos seus princípios e assumindo características ambíguas como forma de manter-se como discurso hegemônico, justificador de determinada ordem.

COVRE (1983), quando analisa a educação durante o regime militar, tenta, através do pensamento dos intelectuais tecnocratas, desvelar seu significado no quadro do chamado capitalismo social para a lógica dominante. Identifica dois aspectos pelos quais esta pode ser apreendida: o primeiro, atendendo ao aspecto individual, como direito social do cidadão e podendo ser pensado como política social; e o segundo, como propiciador de um fator de capital, como qualificador da mão-de-obra, atendendo às necessidades do desenvolvimento tecnológico.

Percebe-se a existência de um certo impasse entre o econômico e o social no interior da concepção tecnocrática de educação.

COVRE (1983, p.196) relaciona a ascensão desta concepção "com a ascensão da hegemonia do monopolismo no embate das visões educacionais das frações do capital", embate este travado entre uma concepção liberal, considerada humanista, em que o homem considerado abstratamente é tido como o fim da educação, e uma visão tecnicista, em que o indivíduo é concebido como meio da educação. A conciliação dessas concepções leva, segundo a autora, ao estabelecimento da relação "produtivismo/distributivismo", em que a valorização pessoal é atendida em proveito das necessidades da comunidade, entendida como vínculo direto com a produção. Portanto, ao mesmo tempo em que favorece o cidadão propicia maior desenvolvimento, contribuindo para o pleno emprego e, conseqüentemente, para o desenvolvimento.

A crítica dessa autora refere-se ao efeito neutralizador do aspecto político da educação provocado por esta concepção. Assinala que a pretensão de imprimir um caráter apolítico à educação encontra na teoria de Mannheim o suporte teórico exigido pelo capital monopolístico diante da necessidade de desenvolvimento de um Estado intervencionista, planejador, para esta fase do capitalismo. A educação é concebida como desvinculada da estrutura social, orientada pelos intelectuais, dado o despreendimento desses sujeitos em relação às classes sociais que lhes permitem a elaboração da chamada "síntese das perspectivas", que corresponde à consciência mais avançada possível em determinado momento histórico.

Para efeito da problemática colocada pelo presente texto, interessa-nos destacar, ainda no pensamento de Covre, a atribuição que esta dá ao pensamento de Mannheim quando considera sua teoria como uma "vertente antitecnocrática da ideologia pós-liberal na medida em que se pretende de- mocrática, em contraste com a vertente tecnocrática mais autoritária". (idem, p. 214)

Segundo a tese de WARDE (1984), na fase de consolidação do capital monopolístico o liberalismo, mais ainda que na fase anterior de transição do capitalismo concorrencial, constitui-se visão de mundo dominante, prevalecendo no senso comum. Para ela, este liberalismo do século XX passou por um processo de rearticulação, que o atualiza perante o Estado interventor, planificador.

\section{NEOLIBERALISMO: O SIGNIFICA- DO DA DESCENTRALIZAÇÃO NAS DIRETRIZES DO BANCO MUNDIAL}

Nesta parte do artigo pretendemos refletir sobre as diretrizes gerais propostas pelo neoliberalismo para as políticas públicas e sobre o sentido assumido pela proposta de descentralização no âmbito educacional.

Partimos do pressuposto de que as orientações do Banco Mundial para a área, em processo de implantação no país, como ocorre em diversos países sujeitos à influência deste órgão, ocorre de forma não-linear, assumindo matizes diferenciados devido à mediação dos governos locais, técnicos e diversos atores sociais. Defendemos, portanto, a validade da ampliação da discussão das características assumidas por estas propostas em decorrência da ampliação da possibilidade de elaboração de propostas que superem os limites impostos pelo Banco Mundial. Apresentadas como única via de desenvolvimento para o mundo moderno, as propostas do Banco Mundial aguçam de forma avassaladora as desigualdades sociais, beneficiando sobretudo o capital, em detrimento do trabalho.

Conforme apresentadas por ANDERSON (1995, p.10), as idéias neoliberais, formuladas desde 1947 pela Sociedade de Mont Pèlerin (fundada por Friedrich Hayek), com a "grande crise do modelo econômico do pós-guerra, em 1973 (...) passaram a ganhar terreno”. Esta crise foi atribuída por esses pensadores ao poder de mobilização da classe trabalhadora, responsável pela corrosão das bases de acumulação capitalista e pelo aumento dos gastos sociais por parte do Estado. Apresentam, portanto, como solução para a crise, o desmantelamento das instâncias de organização operária e uma minimização do papel do Estado no campo econômico e a contenção dos gastos com bem-estar.

O neoliberalismo desenvolve-se sobretudo como reação ao Estado de Bem-estar Social e ao modelo de economia planificada dos países socialistas. O mercado passa a ser o único regulador aceitável para o funcionamento social.

Segundo PAVIGLIANITI (1991), para os neoliberais a relação entre o mercado e o Estado assistencial é contraditória. A contradição apontada consiste no conflito de interesses "entre la libertad económica - que tiende a maximizar los beneficios del empresariado - y el mercado político que tiende a la maximización del poder, para lo qual debe obtener votos a cambio de alguna forma de redistribución". (PAVIGLIANITI, 1991, p.18) Apontam como solução para 
esta questão o enxugamento do funcionamento do mercado político e a liberalização do mercado econômico.

CORAGGIO (1995), ao analisar as propostas do Banco Mundial para a educação, ou seja, as políticas educativas para os países da América Latina, o faz dentro do contexto da globalização e do sentido da política social. Parte da constatação da transição pela qual passam estes países, marcada pela crise do modelo de industrialização e pelo processo global de reforma do Estado, reforma esta que redireciona as relações do Estado com a sociedade e a economia, no sentido de eleger o mercado mundial como principal fonte de capitais de investimentos. Para atrair tais investimentos, os governos destes países têm adotado medidas que visam cumprir determinadas pré-condições que os tornem competitivos, entre outras,

\begin{abstract}
"bajar los costos directos, principalmente salarios y servicios a la producción (...) bajar los costos indirectos, reducir al máximo los derechos ('entitlements') no vinculados a la competitividad, reduciendo el gasto social al mínimo (...) descentralizar el Estado Nacional, passando responsabilidades sociales a las instancias de gobierno y a las comunidades locales". (CORAGGIO, 1995, p.23)
\end{abstract}

A inversão em educação básica é tida como meio de superação da condição de pobreza por parte da população, que teria possibilidade de ser empregada no sistema produtivo.

É interessante destacar que Coraggio identifica nos discursos oficiais do Banco Mundial a necessidade de permitir que os Estados nacionais tenham certo grau de liberdade na adoção de suas políticas públicas, para que, em respeito às realidades locais, possam os recursos ser melhor aproveitados. Aponta também que, entre as diretrizes gerais emanadas por parte do Banco Mundial, a descentralização assume uma conotação política implícita, que ele demonstra no seguinte parágrafo:

\footnotetext{
"Por lo pronto, el banco está determinado a lograr que los sistemas de educación se descentralicen. Aparentemente, de la descentralización se espera que a nível de cada distrito o estabelecimiento se adopten, con mejor conocimiento de las condiciones locales, las combineciones de insumos educativos más eficientes, pero también se espera que reduzca la capacidad de los intereses tradicionales (sindicatos de maestros y burocratas del gobierno central, asociaciones de estudiantes universitários, las élites usualmente beneficiadas por los subsídios indiscriminados) para incidir en la política educativa". (idem, p.24)
}

Como tem ocorrido com outras reivindicações históricas dos segmentos que defendem um projeto democrático popular de sociedade, a descentralização do Estado, via fortalecimento da sociedade civil organizada na definição das políticas públicas, assume, sob as diretrizes neoliberais, matizes radicalmente opostos. Significa a transferência dos encargos para execução dos programas nos setores básicos (educação, saúde, habitação, entre outros) para os municípios e comunidades locais, com o intuito de promover sua privatização, a exemplo das cooperativas de funcionários que vêm se formando, na busca do enxugamento do Estado. Também podemos destacar o processo de enfraquecimento do poder de aglutinação e barganha das diversas formas de associação dos segmentos que representam interesses contrários aos do capital, na elaboração de políticas de caráter global e de repercussão nacional, em razão da pulverização das forças e das formas de organização.

\section{REFERÊNCIAS BIBLIOGRÁFICAS}

ANDERSON, Perry. "Balanço do neoliberalismo". In: GENTILI, P. \& SADER, E. Pós-neoliberalismo. Rio Janeiro: Paz e Terra, 1995.

AZEVEDO, Fernando de. A cultura brasileira. 5.ed. São Paulo: Melhoramentos, 1976.

CARVALHO, Marta Maria Chagas de. "Notas para reavaliação do movimento educacional brasileiro (1920-1930)". Cadernos de Pesquisa, n.66, p.4-11, ago. 1988.

"O novo, o velho e o perigoso: relendo a cultura brasileira". $\mathrm{Ca}$ dernos de Pesquisa, n.71, p.29-35, nov. 1989

CORAGGIO, José Luis. Las propuestas del Banco Mundial para la educación: sentido oculto o problemas de concepción? São Paulo: [mimeo], 1995.

COVRE, Maria de Lourdes Manzini. A fala dos homens: análise do pensamento tecnocrático (1964-1981). São Paulo: Brasiliense, 1983.

DE DECCA, Edgar Salvadori. O silêncio dos vencidos. São Paulo: Brasiliense, 1984.

DURKHEIM, E. Sociologia, educação e moral. Porto: Rés Ed., 1984.

HORTA, José Silvério Baia. "As diferentes concepções de 'diretrizes e bases' e a questão do nacional na história da educação brasileira". Cadernos Anped, n.2, p.5-13, 1989.

IANNI, Octavio. Estado e planejamento econômico no Brasil. Rio de Janeiro: Civilização Brasileira, 1971.

PAVIGLIANITI, Norma. Neoconservadurismo y educación. Buenos Aires: Coquena Grupo Editor, 1991.

SCHWARTZMAN, Simon et al. Tempos de Capanema. Rio de Janeiro/ São Paulo: Paz e Terra/EDUSP, 1984.

TEIXEIRA, Anísio. Educação no Brasil. 2.ed. São Paulo: Nacional, 1976.

WARDE, M.J. Liberalismo e educação. São Paulo, 1984. Tese - Pontifícia Universidade Católica. Programa de Estudos Graduados em História e Filosofia da Educação. 